\title{
レーザ照射による超電導体の接合
}

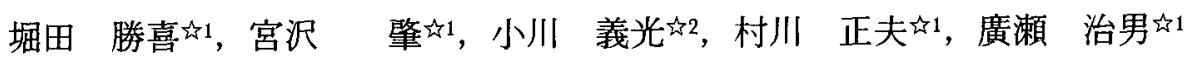

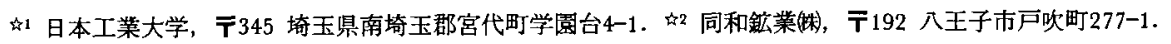

\section{Connecting Superconductors by Laser Irradiation}

\author{
Katsuyoshi Hotta ${ }^{\hbar 1}$, Hajime Miyazawa ${ }^{4}$, Yoshimitsu Ogawa \\ Masao Murakawa ${ }^{\text {\1 } 1}$ and Haruo Hirose \\ นิ1 Nippon Institute of Technology, 4-1 Gakuendai Miyashiro-machi Minamisaitama-gun, Saitama 345 \\ «2 Dowa Mining Co., Ltd., 277-1 Tobuki-cho, Hachioji 192.
}

\section{Received February 15, 1995}

A study on connecting of supercondoctors through laser treatment was conducted. Two kinds of Bi systems i. e., 2223 phase(sintered bulk) and 2212 phase (thin film prepared on $\mathrm{MgO}$ substrate) were used as the substances to be connected. Powders of the system which were pasted with two kinds of solvents, 2 butoxyethyl acetate and mixture of ethyl cellulose and terpineol, were used as the medium materials. Two pieces of respective specimen filled with the medium between them were installed on a jig system and settled on an $X-Y$ table to be exposed to laser beam irradiation. A $160 \sim 350$ w output $\mathrm{CO}_{2}$ laser beam accompanied by oxygen gas blow was irradiated, along the contact line of the substance, onto the medium at a speed $10 \mathrm{~mm} / \mathrm{min}$. Before laser treatment, the electric resistance of all specimen revealed almost constant value of about $600 \Omega$ at temperature range concerned. After laser treatment, for the specimen which used the medium powder pasted with mixture of ethyl cellulose and terpineo1. Tc(end) of $67.6 \mathrm{~K}$ and $47.0 \mathrm{~K}$ was obtained for 2223 phase and 2212 phase respectively, which leads to the connection of superconductors. key words

superconductor. Bi system, connection, medium material, solvant

\section{1 楮言}

著者らは,これまでに大面積超電導厚膜の作製 法として溶謝法により製膜し，超電導化の方法と して大気中で大面積を処理できるレーザを使用す る方法を試み，同方法が溶謝膜の超電導化に有効 な手段となることを示し1?，Bi系バルク材表面に
レーザ照射をしたとき，超電導特性はX線回折に おいて，レーザ照射前に比べ高Tc相の強度が上昇 することも示した ${ }^{2)}$.また，Bi系超電導バルク材 を2つ組合せ，接合部に同系の媒体を入れ，レー ザを照射することが，バルク間の形成に有効な手 段となる可能性を示した ${ }^{3 /}$ 。本報告では,レーザ 
照射による超電導体の接合について検討した.

\section{2 実験方法}

バルク試料の作製は, $\mathrm{Bi}_{2} \mathrm{O}_{3}, \mathrm{PbO}_{2} \mathrm{SrCO}_{3}, \mathrm{CaCO}_{3}$, Cu0(純度99.9\%以上)の粉末を組成式Bio.85Pbo.35 $\mathrm{Sr}_{1}$. 90 oCa 2.05Cu3.050y(2223組成)となるように科 量し，大気中で3時間混合した。この粉末を大気中 で $800^{\circ} \mathrm{C} 12$ 時間仮焼成した。 その後，粉砕し 325 メ ッシュのふるいを通し，大気中で $850^{\circ} \mathrm{C} 50$ 時間本 焼成した．得られた粉末を325xッシュのふるい を通るように粉砕し， $12 \times 70 \times 2.5 \mathrm{~mm}$ の角柱状に压 力 $294 \mathrm{MPa}$ で成形し，大気中において $850^{\circ} \mathrm{C} 50$ 時間 焼成した.このバルク材は $\mathrm{TC}$ ( end $)=98.5 \mathrm{~K}$ を示し た。一方，組成式 $\mathrm{Bi}_{2} \mathrm{Sr}_{2} \mathrm{CaCu}_{2} \mathrm{O}_{\mathbf{z}}(2212$ 組成)につ いては先の 2223 組成と同様に作製し，本焼成粉末 を $\mathrm{Mg} 0$ 基板上にスクリーン印刷し， $885^{\circ} \mathrm{C} て ゙ 5$ 分間 部分溶融し $0.1^{\circ} \mathrm{C} / \mathrm{min} て ゙ 850^{\circ} \mathrm{C}$ まで冷却し，その後

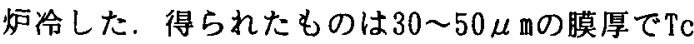

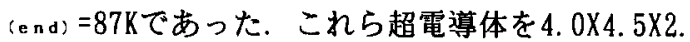
$0 \mathrm{~mm}$ の大さにカットし，2ピースを用いて接合の ための試料とした。またこれとは別に接合しやす くするための媒体として，本焼成した同系の超電 導体粉末にエチレングリコールーnーブチルエーテ ルアセテート（2-ブトキシエーテルアセテート） やエチルセルロースとテルピネオールの混合液等 を混ぜ合わせぺースト状にし，接合面に塗布した。

このとき接合面に対し垂直方向から軽くプレス しながら，熱伝導性の良い真銿を台座にした治具 に納めた。レーザは，図 1 に示すようにCO2 ザを使用し，酸素ガスを98kPaの圧力で吹き付け ながら，出力 $160 〜 350$ W，デフォーカス $120 \mathrm{~mm}$ 一定 として照射し，接合面に沿って $10 \mathrm{~mm} / \mathrm{min}$ で5往復

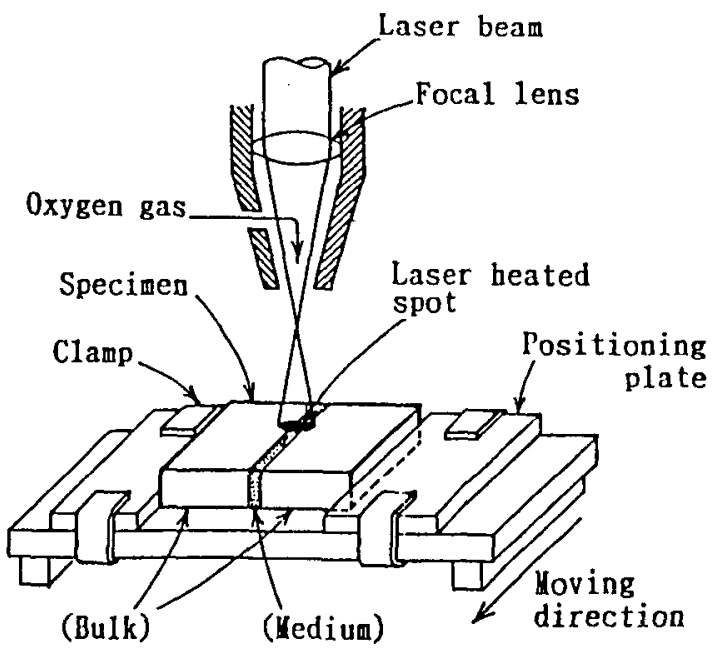

Fig. 1 Schematics of experimental apparatus and setup of specimen.
した。評価は直流四端子法による温度一電気抵抗 特性, SEM観察で行った。

\section{3 実䀦結果並びに検討}

図 2 にBi系2223組成の超電導バルク材を $2 つ$ 組 み合わせたとき，接合部におけるレーザ照射前と 各種出力でレーザ処理したときの四端子法による 温度一電気抵抗特性曲線を示す、レーザ照射前の 試料においては，いずれの試料についても抵抗值 は約 $600 \Omega て ゙$ 電気的につながっているが，温度を 下げても抵抗值は変化せず温度依存性は見られな かった、エチルセルロースとテルピネオールの混 合液を混ぜたペーストを接合面に塗布した 2223 組 成の試料に，出力170Wでレーザ照射した後の接合 部の特性は， $300 \mathrm{~K}$ ときの電気抵抗は $2.53 \Omega$ と非

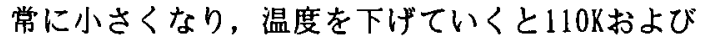
80K付近で高Tc相および低Tc相のTC(onset)が見ら れたが，47Kでも $0.5 \Omega$ を示しTC (end)には至って いない，レーザ出力を200Wと大きくすると，300K

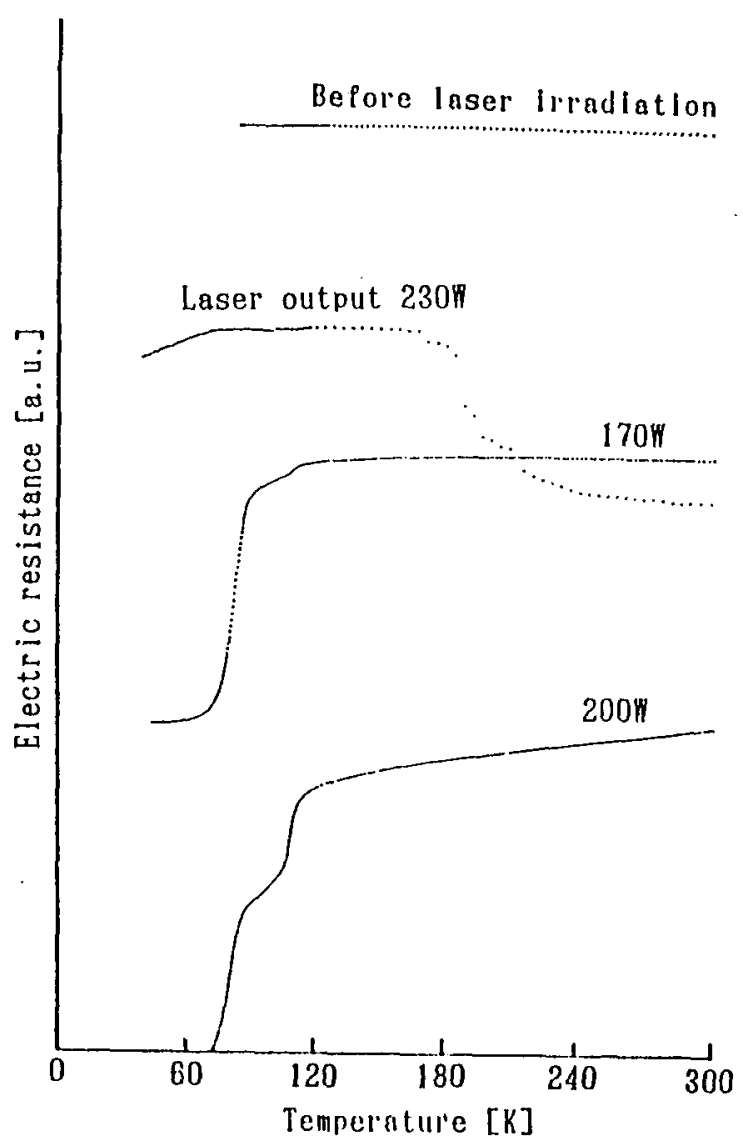

Fig. 2 Temperature vs electric resistance for samples with phase 2223 before and after laser irradiation. 
の電気抵抗は $164 \mathrm{~m} \Omega$ とさらに小さな値を示し, 高 Tc相と低Tc相のTc(onset)が観察され $67.6 \mathrm{~K} て ゙ T c$ ， end)を示した．230Wの出力でレーザ照射した結果

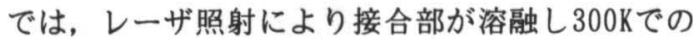
電気抵抗は $2450 \Omega$ と非常に大きくなり超電導特性 は示さなかった。これらの傾向は，接合部に2-ブ トキシエーテルアセテートのペーストを用いた場 合でも同様の特性を示した. 以上の結果から,レ 一ザ出力は接合部の表面が溶融する直前の出力が 最適であることがわかった．

図 3 に2212組成のバルク試料を用いて 2 つ組み 合わせ，接合部にレーザ照射をする前と，表面が 溶融する直前の出力 350 Wでレーザ照射したときの 温度一電気抵抗特性を示す.レーザ照射前は2223 組成のときと同様に約 $600 \Omega$ の特性を示した.レ 一ザ照射することにより $300 \mathrm{~K}$ の電気抵抗は $2.55 \Omega$ を示し, Tc (onset)をすぎると急激に低下し，そ

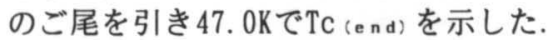

図 4 はレーザ照射した後にTc (end) を示した 222 3組成の試料の接合部をカットし，エッチングせ ずそのままの状態を観察したSEM像を示す。レー

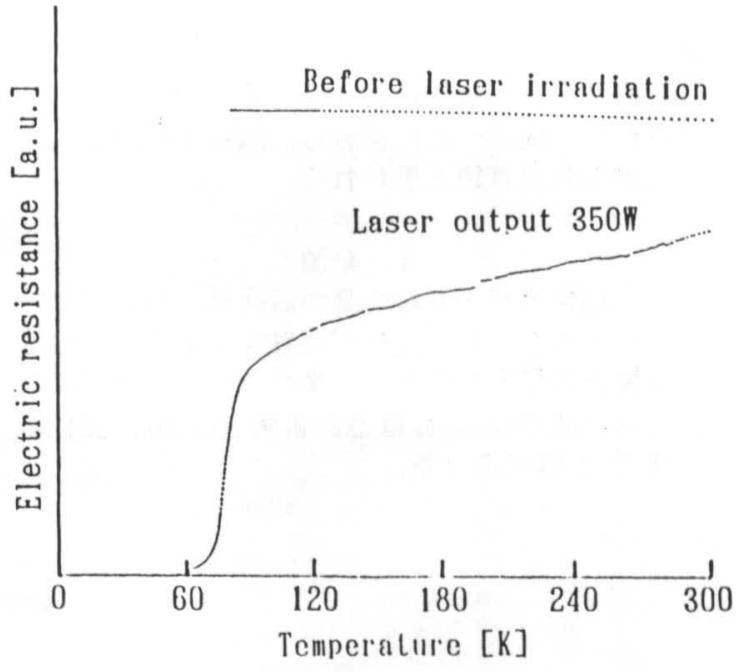

Fig. 3 Temperature vs electric resistance for samples with phase 2212 before and after $350 \mathrm{~W}$ laser irradiation.

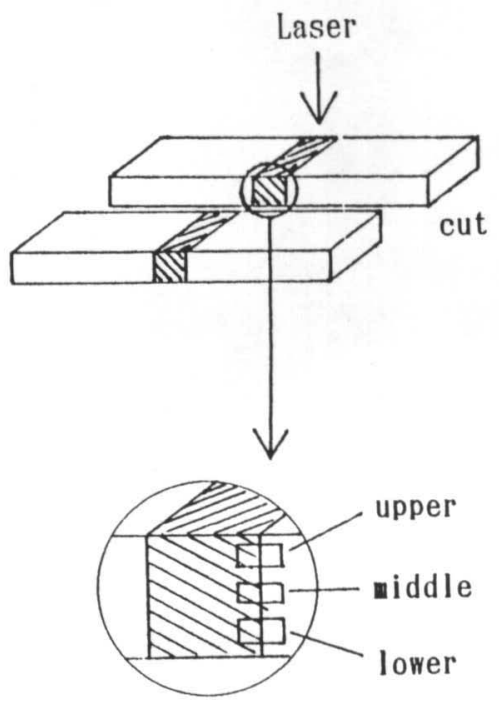

(a) Schematics of cross sectional view of connected portion

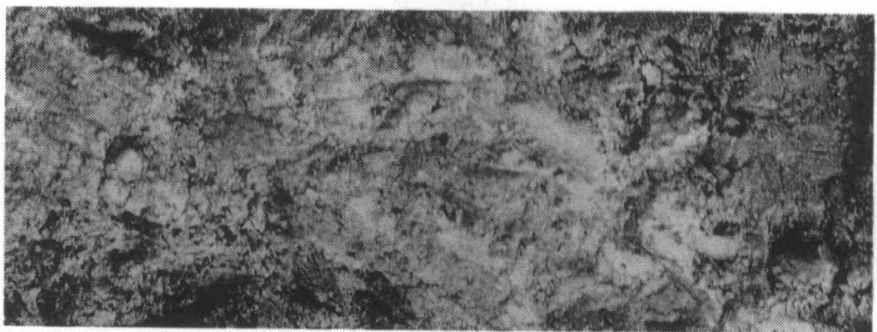

(b) upper part

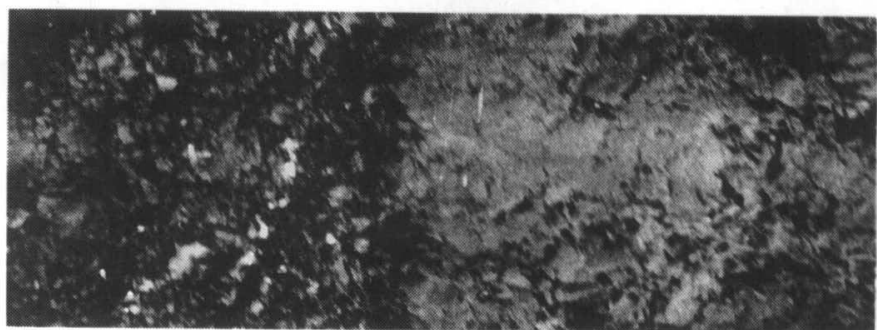

(c) middle part

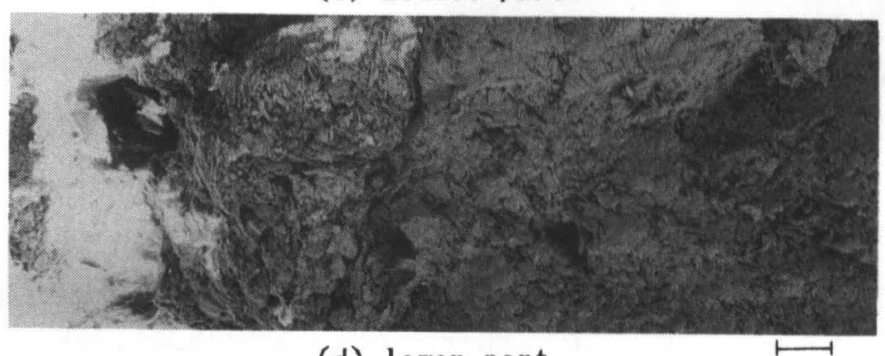

(d) lower part

Fig.4 SEM images of the cross sections of the connecting part for the sample cut off see (a) using diamond cutter after laser irradiation (no etching). 
ザ照射した表面の近くはバルクとペースト部がわ からないほど非常に良く接合している.しかし， 中程になると粒子状のものも観測され，底部に近 いと熱がこもり接合は良くなるもののクラックが 見られた。底部の白い部分は，試料を埋め込んだ 樹脂か治具の真鍮と思われる。

\section{4 結論}

1. Bi 形超電導バルク材を 2 つ組合せ，接合部に同 系の媒体をいれ，レーザ照射する事により超電 導接合接合することが出来た.

2. バルク間のTc (end) は2223組成で67.6K，2212組 成で47.0Kであった。
3. Tc (end) の低下は，接合部の焼結の程度による ものと思われる。

\section{文献}

1）宮沢，堀田，廣瀬，村川：粉体および粉末治金， 39(1992) PP. 748-751.

2）堀田，宮沢，村川，廣瀬。船戸：粉体および粉末 冶金, 41 (1994)PP. 412-415.

3）宮沢，䏱田，船戸，村川，廣瀬：粉体および粉末 冶金, 41 (1994)PP. 1516-1519.

K. Hot ta, H. Mi yazawa, K. Funat o, M. Murakawa and H, Hirose:Physica C 235-240 (1994)PP. $3429-3430$. 